\title{
Situational Analysis of Distributed System and its Effectiveness in Area of Power System
}

\author{
G.Raghavendra \\ Associate. Prof: Dept of Electrical \& Electronics \\ Engg. \\ R R Institute of Technology \\ Bangalore, India
}

\author{
Manjunath Ramachandra, Ph. D. \\ Senior domain specialist \\ Philips Innovation Campus, Nagavara, Bangalore \\ 560045
}

\begin{abstract}
With the rising need of the power supply in the various part of the world along with growing usage of power driven devices, the area of power sector is on constant look out of an effective solution. In this arena, distributed power system has evolved as a great boon to the cater up the needs of the power supply and thereby avoid the occurrences of the power outage. Compared to the conventional power generation system, distributed generation system reduces the cost as well as complexities that occur in power generation and transmission network. This paper performs the situational analysis of the existing system of the distributed power system and reviews some of the frequently adopted techniques along with the brief discussion of existing system to extract the research gap in this area. The outcome of the study will assist the researcher to have better visualization of the contribution of the past studies.
\end{abstract}

\section{Keywords}

Distributed Power System, Distributed Generation, Power Transmission

\section{INTRODUCTION}

In the area of power generation and supply, distributed network plays a vital role to captivate the dynamic power requirements of the customers. Basically, the power generation system is categorized into centralized and decentralized system. The centralized generations are basically adopted in the industrialized nations where the massive amount of power is generated from natural gas, nuclear, coal, and various plants. However, when it comes to transmission over an extended area, it requires more energy to make up for transmission as well as distribution losses. Although centralized generation has some of its advantage but it cannot cater up the growing demands of the electricity over geographic area. Unfortunately, the literatures have never recognized distributed generation for any formal definition until now [1]. Technically, distributed generation refers to generation of power at the point of consumption. The advantage of using distributed generation is that when the system generates power on the precise location of consumption (decentralized) and not centrally, than it can significantly eliminates the cost, inter-dependences, complexities, as well as inefficiencies associated with the distribution and the transmission system [2]. The importance of the distributed generation of power supply can be elaborated taking the increasing demands of population in our country India. From the last 5 years, India still requires higher demands of electricity with the rise of urbanization and production houses. Even at present, there are various remote parts of India, where either there is no electricity or persistent load shedding exceeding more than intolerable hours sometimes. Because of such scarcity, the cost of electricity went high in our country. Provided quality power supply in such areas is not possible from centralized power system but it requires highly decentralized power supply system. This is because distributed generation has some of the significant advantages [3] as follows:

\subsection{Easy Customization}

Distributed Generation (DG) is much easier to modify, redesign as well as substitute a smaller module allocated to the unique portion of the power system. Tailoring the supply delivery module in usual load voltages are quite easy as paralleling the desired number of standard power modules required for a specific need.

\subsection{Efficient Maintenance}

Using DG system, it is quite efficient to perform localization as well as isolation of faults as compared to the efficient parallel system, hot swapping with minimum downtime.

\subsection{Standardization}

The primary goal of the DG system is to provoke the availability of the standardized modules as well as designs for catering up the power demands of various applications. Hence, better standardization in DG system leads to effective development time as reduced engineering cost.

\subsection{Packaging}

DG system uses effective and modernized hardware system for high power processing that drastically reduces the greater dimension of the conventional hardware used in power supply system.

\subsection{Greater Reliability}

DG system offers greater extent of reliability owing to its advanced design of the distribution system. Even with increased used of components in power supply system, DG system offers minimized stress in both thermal as well as electrical component leading to be better reliability.

\subsection{Efficiency}

DG system offers better reduction in internal resistance as the load voltages reduces and that's why it becomes much more efficient to generate high current with optimal voltage as per the requirement of the customers. It also supports the power demands of the distributed units with massive voltages too. 


\subsection{Optimal Power Density}

DG system offers better power densities of 50 to $100 \mathrm{~W} /$ in $^{3}$ to both commercial and domestic needs. With the rise of modernization in power electronics, distributed systems will undergo further fairer scope of advancement even in near future because of its customization capabilities and flexible design adopted in each components of power system.

This paper therefore discusses various traits of DG system with special emphasis on the research contribution in the same topic. The primary aim of this paper is to find the effectiveness of the available research contribution and elicit significant open issues and research gap at the end of the discussion. Section II of this paper discusses about the significance of the distributed generation followed by brief discussion of technologies used in framing up DG in Section III. Illustrative discussions on Government Policies are given in Section IV using the case study of India. Section V discusses about the frequently used techniques by the various researchers followed by review of existing literatures in Section VI. Finally the open issues and research gap explored from the study are discussed in Section VII and Section VIII respectively. Section IX makes some concluding remarks about the paper.

\section{SIGNIFICANCE OF DG}

With the increasing financial need as well as the enormous growth of population of the India as the case study, there is a higher scope of using better system for DG for catering up the growing demands of the electricity. In India, DG system can fulfill such need as it is highly cost effective as well as ecofriendly in nature. With the inherent advantages of the DG system, it provides higher extent of the reliability as well as optimal quality of the power supply as compared to the conventional system. However, it should be known that DG system has higher number of technologies as some of the technologies are considered highly efficient. Even in the present situation, the rural areas of the India still lacks standard electricity supply as it is quite expensive to set up transmission lines and then performs distribution of power supply in such remote area with lack of facilities and uncertain environment condition associated with such remote areas. Another biggest challenge in India is the deregulation of the energy section has yet not made much progress. However, people have adopted DG only because of losses associated with the transmission and distribution, grid failures, and the issues associated with remote regions. A conventional set of DG system using both renewable and nonrenewable technologies are exhibited in Fig.1

In India, basically conventional generation (centralized) of power supply is still in practice and slowly the DG system has been attracted the attention of various users owing to the potential benefits associated while using it. Using the conventional power generation system has significant flaws which leads to outage which is never a case in DG system [4]. Moreover, usage of conventional system leads to increase in cost as owing to the packaging, maintenance, and failures in long transmission lines, which is never even a probable situation in DG system. The conventional power generation system is also pretty sophisticated in nature as usually the hardware components are quite massive in size while DG systems do not even bother about dimension of the hardware system and it is quite simple to perform installation.
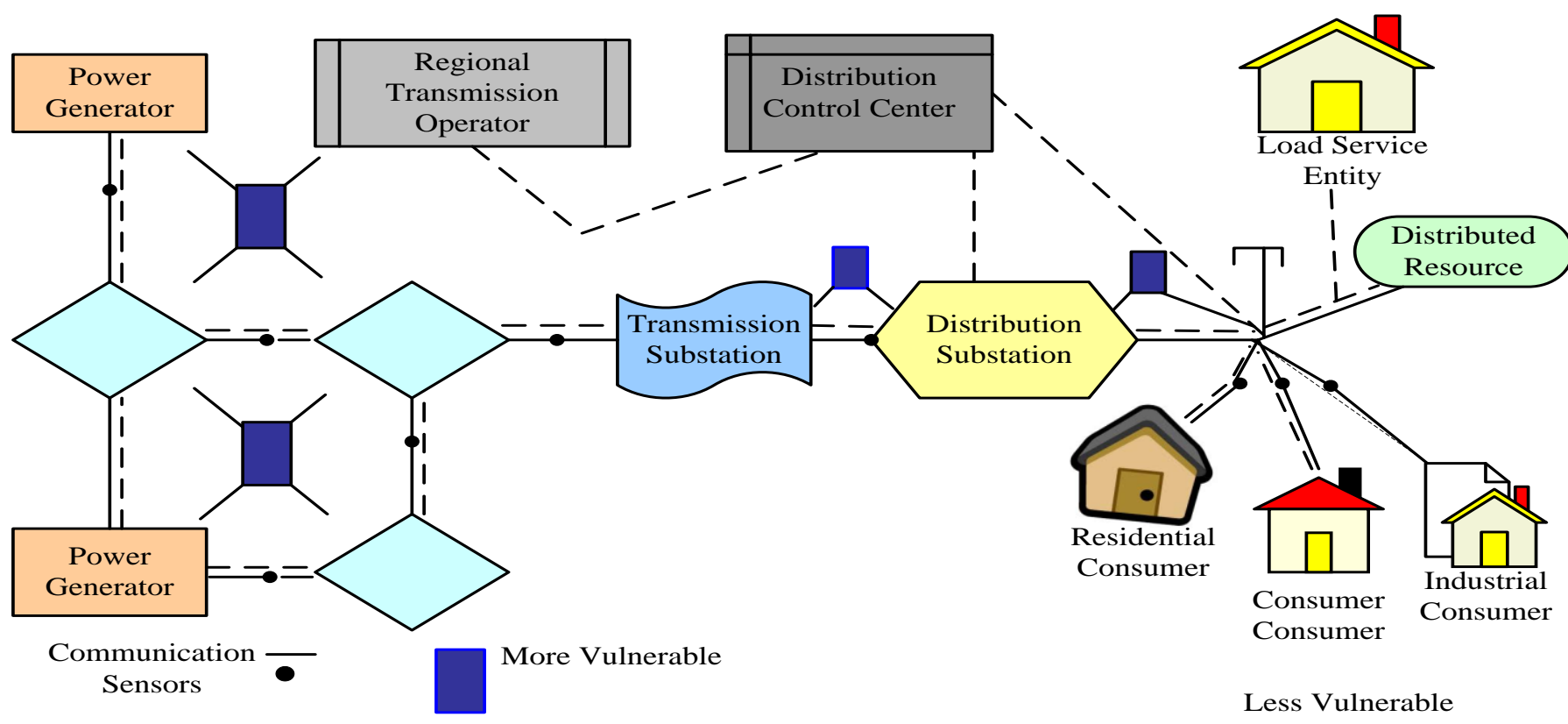

Less Vulnerable

Fig 1: A Distributed Generation System 


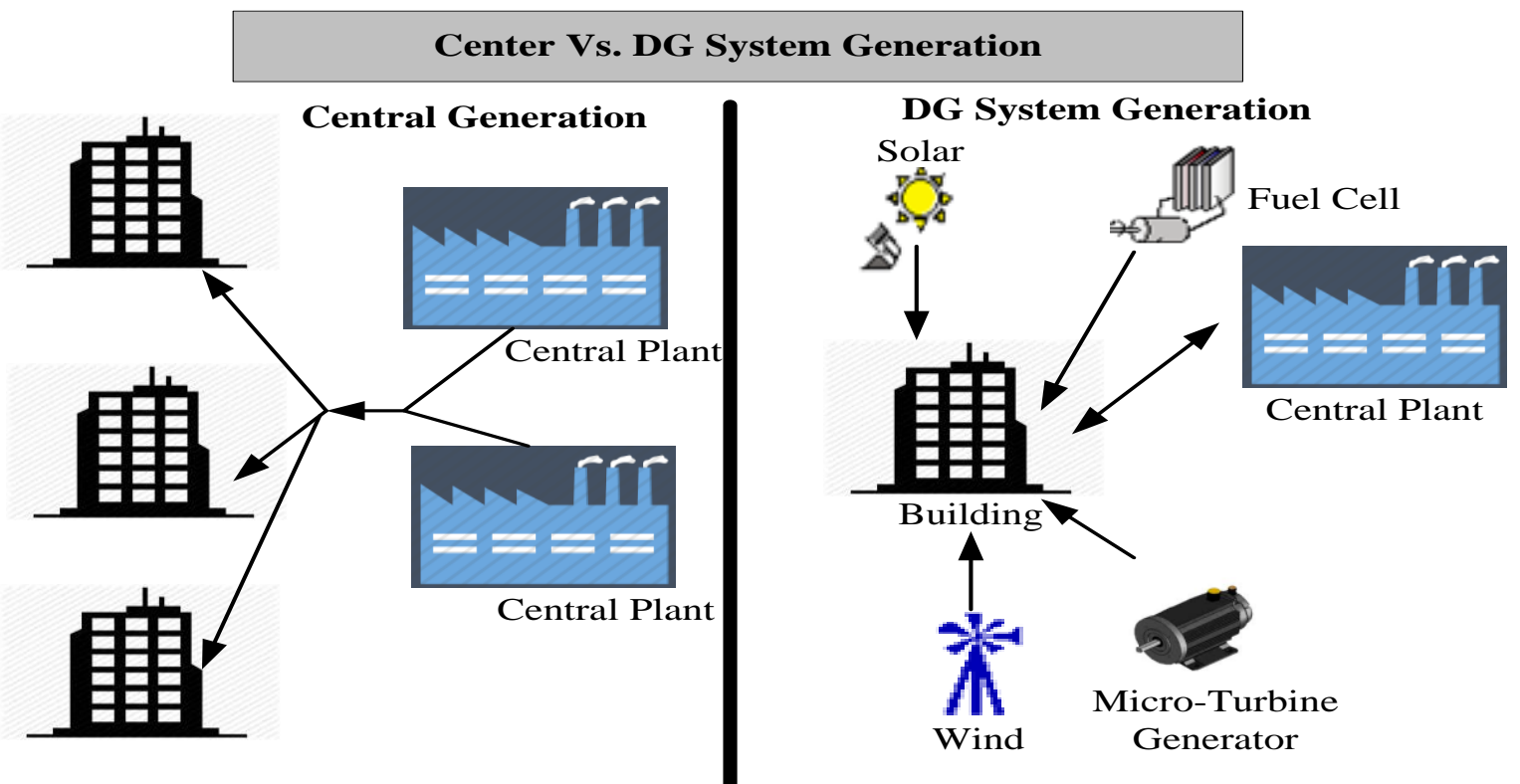

Fig 2: Conventional vs. DG systems in Generation

Although conventional system is an effective method in some cities of India but it can never cater up the growing demands of electricity in rural and remote areas, where DG system is the best alternatives. The differences in conventional and DG system can be cited pictorially in Fig. 2

\section{TECHNOLOGIES FOR DG}

There are a number of technologies are used for distributed generation. The Distributed Generation technologies are following:

\subsection{Wind Turbines}

In wind turbines the wind is used to generate electricity and it does not require long transmission lines. Wind turbines can be used for on-site generation as it does not need setting of infrastructure.

\subsection{Fuel Cells}

Fuel cells have very low NOX and carbon dioxide emission. There are many fuel cells which are under process.

\subsection{Photovoltaic}

Photovoltaic system is consisting of solar panels so it is also known as solar panels. Solar panels are made up of small cells which are connected together that catch solar radiation and convert into electricity.

\subsection{Reciprocating Engines}

Diesel and natural gas are used as fuels in the reciprocating engines, the emission output varies. Almost all engines work in four strokes intake, compression, combustion and exhaustion. Combustion Gas Engine: The combustion gas engine is also termed as mini-turbines or industrial turbine. They can be achieved up to $15 \mathrm{MW}$.

\subsection{Micro-Turbines}

Micro turbines consist of a compressor, combustor, turbine, and a generator. Most micro turbine units are designed for continuous operation with higher electric efficiencies.

\section{GOVERNMENT POLICIES}

Government of India had taking certain policies which aims to provide energy through the use of conventional and alternative sources of energy .Some of the policies of government are as follows:-

- The Electricity Act, 2003 [6] has given a thrust to distributed generation particularly in the context of rural electrification. The Act specifies distributed generation and supply through stand-alone conventional and renewable energy systems.

- The National Electricity Policy notified on 12 February 2005 recommends under the Rural Electrification component, that to provide a reliable rural electrification system, wherever conventional grid is not feasible, decentralized distributed generation facilities (using conventional or non-conventional sources of energy) together with local distribution network be provided.

- Two specific schemes, the Rajiv Gandhi Grameen Vidyutikaran Yojna and the Remote Village Electrification Scheme, will provide up to $90 \%$ capital subsidy for rural electrification projects using decentralized distributed generation options based on conventional and non-conventional fuels.

India has abundant, untapped renewable energy resources, including a large land mass that receives among the highest solar radiation in the world, a long coastline with high wind velocities that provide ample opportunities for both land-based and offshore wind farms, significant annual production of biomass, and numerous rivers and waterways that have potential for hydropower. Promoting renewal energy is the best to cope up with reducing coal consumption and oil bill as well which will contribute to economy. Add to this the Indian economy is expected to grow at over 5\% per annum up to 2030. Distributed Generation is a better solution for rural areas electrification. There certain aspects which lead to the adoption of distributed generation as in traditi0onal generation there T\&D losses, massive grid failure and inaccessibility to remote regions. There are a number distributed technologies are used some of which are not economical for the rural areas 
electrification. Some technologies like solar PV, biomass, hydro power are appropriate for such locations. Some people from electrified villages are also not satisfied with the quality of grid they can also adopt Distributed Generation. For a large and dispersed rural country, decentralized power generation systems, where in electricity is generated at consumer end and thereby avoiding transmission and distribution costs, offers a better solution. Gokak Committee had gone into details about the concept of decentralized generation to meet the needs of rural masses. The main recommendations of the Gokak Committee are as under:

- The concept of Distributed Generation (D.G.) has been taken as decentralized generation and distribution of power especially in the rural areas. In India, the deregulation of the power sector has not made much headway but the problem of T\&D losses, the unreliability of the grid and the problem of remote and inaccessible regions have provoked the debate on the subject.

- The D.G. technologies in India relate to turbines, micro turbines, wind turbines, biomass, and gasification of biomass, solar photovoltaic and hybrid systems. However, most of the decentralized plants are based on wind power, hydro power and biomass and biomass gasification. The technology of solar photovoltaic is costly and fuel cells are yet to be commercialized.

- In so far as the 18,000 villages in remote and inaccessible areas are concerned, the extension of grid power is not going to be economical. Decentralized plants based on biomass, gasification of biomass, hydel power and solar thermal power and solar photovoltaic are the appropriate solution for these areas. A decision with regard to the available options will have to be taken depending on the feature of each site/village.

- As regards the remaining electrified villages, the responsibility should rest primarily with the State Governments. The Govt. of India would, however, act as the facilitator to them.

- As people in many of the electrified villages are very much dissatisfied with the quality of grid power, such villages also encouraged to go ahead with the Distributed Generation Schemes. These should also be the responsibility of the State Governments.

- Though India has made considerable progress in adopting technologies based on renewable sources of energy these are not yet capable of commercial application on a large scale.

- Association of Village Panchayat with Village Level Committees is important for the success of the programme. The fact that the Rural Electric Cooperatives which were established in the 80.s for distribution of power supplied by the SEBs incurred losses need not deter us from trying them out again as these did have some positive features.

\section{FREQUENTLY USED TECHNIQUES}

Although the literatures have archived various techniques and algorithm to introduce the framework of distributed generation of power supply still some of the techniques are found quite common in the literatures. This section will discuss some of the common soft-computing techniques used by prior researchers and will introduce the reason of using such techniques.

\subsection{Artificial Neural Network (ANN)}

The ANN is a black box which correlates the non-linear relationship between output and input without information of system structure. The ANN has been applied to achieve better control strategies especially in a non-linear complex power system. Implementation of ANN was found in the study of Nagalingam [7] and Wanik et al. [8]. Nagalingam [7] designed a grid interface using new controller design using neural network for improving system efficiency. Wanik et al. [8] introduced a predictive policy for managing distributed generation units using optimization principles of ANN.

\subsection{Fuzzy Logic}

Fuzzy logic has been widely used in the control related problems in power system. Contrary to the traditional control which is mostly based on linear zed mathematical model, the fuzzy logic control approach solves the problem based on experience and knowledge about the system. Deployment of Fuzzy Logic has been found in the literature of Kashyap and Kishore [9] as well as Shanti and Vanmukhil [10]. Kashyap and Kishore [9] have designed control architecture to enhance power quality using Fuzzy Logic. Shanti and Vanmukhil [10] performed modelling of integrated hybrid renewable energy system, where the optimization was performed using Fuzzy Logic.

\subsection{Genetic Algorithms (GAs)}

The GA is a global search optimization technique based on operation of natural genetics and Darwinian survival-of-thefittest with a randomly structure din formation exchange. The GA shave been widely applied to solve complex nonlinear optimization problems in a number of engineering fields in general and in the area of AGC of power systems in particular. Adoption of GA was found in the work of Hansen et al. [11] who have introduced a framework for solving smart grid resource allocation problems.

\subsection{Particle Swarm Optimization (PSO) Algorithms}

The PSO conducts search ensuing a population of particles which correspond to individual sin the GA. The PSO is a population based stochastic optimization technique, inspired by social behavior of bird flocking or fish schooling. To ease the design effort and there by improve the performance of the controller, the design of fuzzy PI controller by hybridizing GA and PSO is presented. Usage of Swarm Optimization in designing analog circuit of power electronics was seen in the study of Vural and Yildirim et al. [12]. The authors have used Particle Swarm Optimization to solve the circuitry complexities in distributed generation of power supply.

\subsection{Tabu Search Algorithms (TSA) and Bacterial Foraging Optimization Algorithm (BFOA)}

The TSA is an iterative search that starts from some initial feasible solution and attempts to determine a better solution in the manner of a hill climbing algorithm. The TSA has a flexible memory which main trains the information about the past step of search and use sit to create and exploit the better solutions. Mohanty and Pradhan [13] have used Tabu Search algorithm for addressing gate leakage optimization in power electronics. Baijal et al. [14] have discussed the use of bacterial foraging optimization in prior studies for economic load dispatching. 


\section{EXISTING LITERATURES}

This section discusses about the recent studies being done in the area of distribution of power system, where the recent research work of 2007 to 2014 is discussed on the following categories:

\subsection{Design of Distributed Electricity Framework}

The work done by Gupta [15] has evaluated the atmospheric sensitivity factor for the demand of power supply in Delhi. The experimentation was carried out using regular data on electricity requirement and noticeable temperature for the period 2000-09. The author has used a semi-parametric variable coefficient for the purpose of exploring the influence of the atmospheric parameters on the demands of power supply. The study also depicted the demand of power supply as the U-shaped function of the temperature, where the study also suggested that the increasing part of the temperature-electricity curve as more dominating over the time with an increase in summer temperature. The study also made some forecasting of the bad weather condition on the demands of the electricity as represented by the asymmetric distributed in various seasons.

The study presented by Lopes et al. [16] gave a visualization of the distributed generation of the electric power system. The primary drivers behind the concentration on DG incorporation, particularly of the renewable sort, in numerous nations as far and wide as possible are talked about. A summation of the fundamental difficulties that must be overcome the whole time is introduced. Specific accentuation is set on the need to move far from the fit and overlook methodology of associating DG to electric force frameworks to an approach of coordinating DG into force framework arranging and operation through dynamic administration of conveyance systems and application of other novel ideas.

Bloemink and Green [17] in their study have exhibited the utilization of dynamic compensation with power electronics to expand the level of DG that might be required in dispersion systems. A constraint flow of energy technique was utilized to model gadgets and focus on designing the limit for DG on a specific system. A technique was concocted for programmed situation of compensators and DG to empower a substantial number of cases to be evaluated. The specimen populace comprised of information from about 600 U.K. distribution networks. Shifting evaluations and amounts of shunt, series, and multi-terminal compensators were considered for this study.

Ng-Molina et al. [18] have used distributed amplifier framework based on energy recycling schemes. The system permits the amplifier gain to be improved while giving ideal yield power and an impeccable data match inside a moderate transfer speed. The perfect execution of this novel circulated amplifier is evaluated in this study. Limits presented by bungle and misfortunes in the door line have likewise been surveyed. A model of such an enhancer has been planned, fabricated and measured. The test results show its suitability as an ideal classan active power combiner with improved gain and superb information match.

Maharjan et al. [19] presented different fossil-fills and numerous renewable vitality sources built service organizations with respect to the supply side, and propose an end-client arranged service organization choice plan to minimize client costs. They figure the issue as an amusement, joining the vulnerability connected with the force supply of the renewable Sources, and demonstrate that there exists Nash balance for the game logic. To further lessen clients' expenses, they create a joint plan by coordinating shift able load scheduling with service organization choice.

Ji et al. [20] created a spatial-temporal and non-stationary arbitrary procedure to model vast scale disturbances of power circulation impelled by serious climate. The model joins no stationary disappointment and recuperation irregular courses of action with system structures. Dynamic failures and recuperation neighborhoods are characterized to describe a topological system structure.

\subsection{Cost of Electricity Distribution}

Berges et al. [21] in their study have proposed concentrating on the computational side of the result. Equipment will continue enhancing over the long haul, and getting high recurrence tests for current and voltage waveforms will get to be less immoderate. Notwithstanding that, they imagine utilizing other sensor information to improve distinguishment (e.g., light power, relative dampness). From this, the following period of examination can start: advancement of a NILM framework utilizing sensor combination and mechanized occasion order.

Xia et al. [22] showed a metering expense minimization model that is fabricated for the metering outline of a particular $M \& V$ EE lighting venture. The streamlining issue is tackled and the example sizes of each one gathering are resolved. Furthermore, the negligible metering expense of the testing is chosen to accomplish the required estimation exactness of the general task.

Besnard et al. [23] exhibited a model for improving the maintenance support firm of an offshore wind farm: the area of maintenance accommodation, the quantity of specialists, the decision of exchange vessels, and the utilization of a helicopter. The model incorporates an examination of a transportation system utilizing option transportation implies, a lining model of upkeep exercises, and a financial model of the support help association. A case focused around a non specific 100 wind turbine 5-MW wind ranch is utilized to show the application of the model.

$\mathrm{Xu}$ et al. [24] considered this essential issue of cost in power supply in their stud. To begin with, the idea of normal cost of power is characterized to measure the normal generation expense of power utilizing different gadgets. Second, a solace model of tenant is created to catch the tradeoff between thermal solace and expense. Human building cooperation permits the client to conform their temperature set reaches as per the mean cost of electricity progressively. Third, an iterative result strategy is produced to tackle the supply request coordination advancement issue. Numerical cases demonstrate that critical vitality sparing is conceivable through investigating the delicate solace prerequisite of the inhabitants, and the iterative technique attains an answer which is near that of the unified strategy, yet in a much speedier manner. They trust this work brings understanding to building vitality sparing all in all.

\subsection{Optimization of Electricity Distribution}

Farhat et al. [25] introduced a bibliographical overview of the work distributed on the application of diverse optimization systems used to fathom the fleeting aqueous coordination issue. Different streamlining systems that handled the issue are outlined and ordered with their points of interest and restrictions having been discriminatingly examined. The study gave a general writing overview and a rundown of distributed references on the point planning to offer the vital rules with respect to this dynamic exploration range. 
Bernardon et al. [26] showed another calculation for lessening power losses and enhancing dependability on system reconfigurations. The calculation is focused around fuzzy multi-criteria decision making and is actualized in an evidence of-idea device.

Voll et al. [27] proposed a novel methodology for the modelbased without superstructure combination and advancement of appropriated energy supply frameworks using the way of evolutionary computation. A mutation administrator replaces parts of energy supply frameworks by option plans. The mutation administrator picks the option plans focused around a set of nonexclusive substitution standards. To minimize both the quantity of substitution principles and unimportant design alternative produced amid mutation, all pertinent energy change innovations are arranged into a progressively organized chart.

Li et al. [28] explored the effective meter information gathering issue in smart grid by investigating the secondary spectrum market in cellular systems. With the motive of lessening the aggregate expense, they propose an issue for discovering the ideal plan for channel determination and transmission scheduling plan.

Sadeghkhani et al. [29] have introduced a radial basis neural system to study transformer exchanging over-voltages to accomplish great generalization ability. The proposed ANN methodology is tried on a halfway 39-bus New England test framework.

Abd-Elkader et al. [30] have proposed a passive strategy for islanding recognition for a wind farm power generation framework utilizing artificial neural system. The results demonstrate that the proposed islanding identification technique can discover islanding operation quick in an effective way.

Priya and Prakash [31] have exhibited a strategy for the ideal area and estimating of generator in Distributed generation in distribution frameworks utilizing genetic algorithm. The proposed system is modified and tried in a 16 bus distribution framework

Harrison et al. [32] have proposed a set of methods to characterize the ideal areas and limits of distribution generation as a method for guaranteeing that the greatest measure of distribution generation might be associated with existing and future systems.

Behbahani et al. [33] have assessed the transient dependability of power frameworks with expanded penetration level of appropriated generation resources based on ascertaining the most extreme rotor speed deviation index using Support Vector Machine.

\section{OPEN ISSUES}

The areas of the distributed power are found to encounter following open issues inspite of some of the significant efforts in the last decade.

\subsection{Distribution Network Issues:}

It was seen that majority of the prior studies although have concentrated on the resources, capacity, distributed generation of the power supply and utility, but they have not included much of the illustration of the network or its associated issues in distributive power supply. Some of the contradictory factors in this discussion pertaining to distribution design and transmission network are jotted as follows:
- The preliminary point is that the discussed distribution network is frequently designed for the various objectives than specifically considering transmission network of the power supply. The prime distinction factor in this regard is that the distribution framework are usually not framed up for the connection of the associated power generation devices e.g. the connection of the distributed generation very often lead to the alteration in the fault-current and therefore a redesign of the local fault protection framework might be needed. Moreover, the distribution networks have usually the radial or loop design and doesn't considers the meshed based design what really is required in transmission network, and hence the trade-off between the distribution network and transmission network surfaces. This is also the reason for the unidirectionality of the power flow in the distribution network with fewer redundancies.

- The second point in the discussion is the high voltage lines that have low resistivity as compared to low voltage line in the conventional distribution network. However, in the transmission lines, the influence of the power lines on the voltage drop is usually very small as its specific magnitude is much less than the reactance. Therefore, the reactance is very crucial factor in this viewpoint for the drop of voltage as well as the line losses. However, in rural distribution framework, the resistivity of the distribution lines is frequently higher to the inductivity. Therefore the distribution line resistivity causes a potential proportion of the drop of the voltage along the distribution lines as well as the line losses. Hence, the connection of the distributed generation can have potential impact on the local voltage level.

- The third point in this discussion is the lower end of voltage of the distribution framework that are usually not associated with the Supervisory Control and Data Acquisition framework that are practiced in the existing system. The data aggregation is needed for the control of the distribution framework as well as the DG units is therefore problematic and challenging. The sophistication in the data aggregation for the control system in the competitive markets maximizes owing to the fact that independent power generators operate their DG units as per the market price signals that do not often necessarily corresponds to the system's control requirement in the local distribution zone.

\subsection{Connectivity Problem}

One of the challenging issues in this discussion of the open issues is that the generation of the power supply and the connectivity of the power grids of the DG technologies can be potentially different from the conventional centralized power generation system. It was also seen that the maximum power sectors deploys synchronous generators that have the ability of the controlling the reactive power output. It can be cited by an example that a large DG unit that uses the natural gas for example deploys synchronous generators. While medium-sized and small DG systems frequently uses asynchronous generators, which is also termed as induction generators. Induction generators are potentially cost effective as compared to the synchronous generators. It was also seen that the asynchronous generators have different operational properties as compared to the synchronous generators. However, one of the limiting factors is that a directly grid-connected asynchronous generator cannot provide the reactive power. The reactive power is derived from the asynchronous generator 
using grid during the start-up steps as well as in duration of the operation.

The study also furnished some of the solution for mitigating the demerits of grid-connected asynchronous generators. Many of the producers of the DG systems have actually deployed a massive range of capacitors as well as converters used in power electronics. Evolution of various micro-systems like fuel cells, photovoltaic system, micro-hydro turbines, and batteries etc that have to be connected via an interface to the grid as these micro-systems generates direct current. It was also found that advanced power electronic interfaces also furnished multiple alternatives to convert $\mathrm{DC}$ to $\mathrm{AC}$ voltage and current with desired frequency. Various possibilities of grid integration were also seen using new converters. Voltage control can be done using power converters in distribution network too, which usually give rise to power fluctuation in the distribution network. This is a big issue. Another issues surface when such massive alternatives of grid connectivity of distributed network perform the evaluation of the grid integration issues very complex. Moreover the local network conditions have a significant influence on the relevant integration issues for which each network will need an illustrated analysis. Hence, in order to reduce such connectivity problems, a precise industry standard should be developed for the interface design for distributed generation that covers internal as well as external control issues. At present, majority of such distributed network operators relies on the frequently used interconnection standards regarding the connection of DG resources for accomplishing a safe and robust network operation. Majority of such standards were formulated based on the guidelines of IEEE and ANSI, however, such standards do never differentiate between micro PV frameworks and medium-sized CCGT power station. Moreover, it was also found that the owner of the DG units as well as the distribution network operator frequently conflict regarding the precise connectivity standards. These are the open issues, which should be addressed in the upcoming studies by researchers.

\section{RESEARCH GAP}

After reviewing the literatures discussed in the previous section, following research gaps are explored.

- Various studies in past has mainly focused on experimenting with narrowed case studies of power generation, which make the scope of solution very limited in dynamic need of large scale consumers.

- Frequent adoption of neural network, genetic algorithm, support vector machine, and various other evolutionary processes as a part of optimization approach are time consuming because of its inherent dependency on training phase and dataset.

- Studies towards cost optimization in dynamic distributed power system are very few.

- The prior implementation is majorly done considering the circuitry principles where design optimization finds hard to increase the scope of evaluation.

- No effective or standardized model yet seen that are frequently adopted for benchmarking the work presented by prior authors.

\section{CONCLUSION}

This paper has presented the brief discussion of the evolution of distributed generation of power supply from the conventional centralized system of generation, where the case study of India was take to support the overlay of the discussion. The paper has discussed some of the potential advantages of the distributed generation as compared to conventional techniques. Widely used technologies for DG are found to be Wind Turbines, Fuel Cells, Photovoltaic, Reciprocating Engines, and Micro-Turbines. The paper has also identified some of the frequently used techniques as ANN, GA, Fuzzy Logic, and Swarm intelligence using the prior studies of distributed electricity generation. Finally the paper has discussed about the significant contribution of the existing literatures with respect to distributed design, cost, and optimization followed by brief highlights of the open issues and research gap being explored from the study. This paper talks about the pertinent issues and goes for giving a general definition to dispersed force era in aggressive power markets. When all is said in done, DG might be characterized as electric power generation inside appropriation systems or on the client side of the system. Furthermore, the terms dispersed assets; appropriated limit and circulated utility are talked about. System and association issues of appropriated generation are exhibited, as well. Besides, the system coordination of dispersed generation is an exceptionally mind boggling issue, which might be essentially not the same as customary system mix of force era into transmission systems. Consequently, further research is obliged in regards to the investigation of the effect of appropriated generation on the solid and financial operation of dispersion frameworks. Consequently it is vital to consider the profits of distributed generation, e.g. decrease of system misfortunes, and in addition extra expenses, e.g. the upgrade of the assurance framework. This paper is the brisk audit of Distributed Generation in India, its need, essentialness in not so distant future. This paper gives how Traditional Generation is varying from Distributed Generation. As per current condition the India is all in all correct for the improvement of dispersed era. There are distinctive innovations in which the appropriated era attempts to get powerful yield that could be recharging and non-restoration. Certain approaches are embraced by legislature of India for giving vitality security. Appropriated era from Indian situation it is a finer choice for giving provincial jolt furthermore give vitality security. There are some key issues and difficulties that are attempting settle in future. Fuel conveyance is very extreme in creating nations like India so control generation from restoration vitality assets may be legitimate. In this paper we are attempting to concentrate on the point that in future Distributed Generation will assume a noteworthy part in providing rural electrification.

\section{REFERENCES}

[1] Bollen,M.H.2011.Integration of Distributed Generation in the Power System. John Wiley \& Sons.Technology \& Engineering, pp. 544

[2] Massey,G.W.2011.Essentials of Distributed Generation Systems, Jones \& Bartlett Publishers,Technology \& Engineering,pp. 204

[3] Mammano,B.2009. Distributed power system. Applied Power Electronics Conference and Exposition APEC

[4] Sioshansi,E.P.2014.Distributed Generation and its Implications for the Utility Industry. Academic Press, 26Jun-2014 - Technology \& Engineering,pp.552

[5] Saxena,A., Chandra, S.2013. Rural Electrification in India using Distributed Generation: Current Scenario. Government Initiatives, Regulatory \& Technical Issues, American International Journal of Research in Science, Technology, Engineering \& Mathematics 
[6] http://powermin.nic.in/acts_notification/electricity_act200 3/preliminary.htm

[7] .Nagalingam, M., Kandasamy, C.P.,.Manokaran,T.2014. Analysis of PEM Fuel Cell Power Supply for Grid Interface Using ANN Controller. International Journal of Advanced Research in Electrical, Electronics and Instrumentation Engineering, Vol. 3, Issue. 4

[8] Wanik, M.Z.C., Erlich, I., Mohamed, A., Shareef, H.2010. "Predictive Var management of distributed generators. In IPEC, 2010 Conference Proceedings, pp. 619-624

[9] Kashyap,D.S., Kishor, M.2012. Fuel Cell Distributed Generation Systems Using Fuzzy Logic Control. International Journal of Engineering Research and Applications (IJERA), Vol. 2, Issue. 3, pp.776-782

[10] Shanthi,T., Vanmukhil, A.S.2014. Fuzzy Logic based MPPT Control of Hybrid Power Generation System. International Journal of Computer Applications, Vol.86, No. 1

[11] Hansen, T., Roche, R., Suryanarayanan, S., Siegel, H. J., Zimmerle, D., Young, P. M., Maciejewski, A. A.2012. A proposed framework for heuristic approaches to resource allocation in the emerging smart grid. In Power System Technology (POWERCON), IEEE International Conference, pp. 1-6

[12] Vural, R.A., Yildirim, T.2012. Analog circuit sizing via swarm intelligence. International Journal of Electronics and Communications, Vol. 66, pp. 732-740

[13] Mohanty,S.P., Pradhan, D. K.2009. Tabu search based gate leakage optimization using DKCMOS library in architecture synthesis. JDT 3

[14] Baijal, A., Chauhan, V.S., Jayabarathi, T.2011. Application of PSO, Artificial Bee Colony and Bacterial Foraging Optimization algorithms to economic load dispatch: An analysis. International Journal of Computer Science Issues, Vol. 8, Issue. 4, No. 1

[15] Gupta,E.2012. Global warming and electricity demand in the rapidly growing city of Delhi: A semi-parametric variable coefficient approach. Energy Economics, Vol. 34 No. 5, pp.1407-1421

[16] Lopes, J.A.P., Hatziargyriou, N., Mutale, J., Djapic, P., and Jenkins, N.2007.Integrating distributed generation into electric power systems: A review of drivers, challenges and opportunities. Electric Power Systems Research, Vol. 77, No. 9,pp. 1189-1203

[17] Bloemink, J. M., and Green, T.C.2013.Benefits of Distribution-Level Power Electronics for Supporting Distributed Generation Growth. IEEE Transactions on Power Delivery, Vol. 28, No. 2

[18] Ng-Molina, F.Y., Teresa M. Martín-Guerrero, Carlos Camacho-Peñalosa.2013.Power recycling concept applied to distributed Amplification. IEEE-Microwaves, Antennas \& Propagation, Vol. 7, Iss. 15, pp. 1207-1214

[19] Maharjan,S., Zhang, Y., Gjessing, S., and Tsang, D.2014. User-Centric Demand Response Management in the Smart Grid with Multiple Providers. IEEE Transactions on Emerging Topics in Computing

[20] Wei, Y., Ji, C., Galvan, F., Couvillon, S., and Orellana, G.2013. Dynamic modeling and resilience for power distribution. In Smart Grid Communications
(SmartGridComm), IEEE International Conference ,pp. $85-90$

[21] Berges, M., Goldman, E., Matthews, H. S., and Soibelman, L.2008. Training load monitoring algorithms on highly sub-metered home electricity consumption data. IEEE-Tsinghua Science \& Technology, Vol. 13, pp. 406411

[22] Xia, X., Ye, X., and Zhang, J.2012. Optimal metering plan of measurement and verification for energy efficiency lighting projects. In Energy Effciency Convention (SAEEC), pp. 1-8

[23] Besnard, F., Fischer, K., Tjernberg, L. B.2013. A model for the optimization of the maintenance support organization for offshore wind farms.Sustainable Energy, IEEE Transactions , Vol. 4, No. 2, pp. 443-450

[24] Xu, Z., Jia, Q-S., and Guan, X.2014.Supply Demand Coordination for Building Energy Saving: Explore the Soft Comfort. IEEE Transactions on Automation Science and Engineering, pp. 1-10

[25] Farhat, I.A., E-Hawary, M. E.2009. Optimization methods applied for solving the short-term hydrothermal coordination problem. Electric Power Systems Research , Vol.79,No. 9, pp. 1308-1320

[26] Bernardon, D.P., Garcia, V. J., Ferreira, A. S. Q., and Canha, L. N.2009.Electric distribution network reconfiguration based on a fuzzy multi-criteria decision making algorithm. Electric Power Systems Research, Vol 79, No. 10, pp.1400-1407

[27] Voll, P., Lampe, M., Wrobel, G., and Bardow, A.2012. Superstructure-free synthesis and optimization of distributed industrial energy supply systems.Energy, Vol.45, No. 1,pp. 424-435

[28] Li, P., Guo, S., and Cheng, Z.2013. Joint Optimization of Electricity and Communication Cost for Meter Data Collection in Smart Grid. Emerging Topics in Computing

[29] Sadeghkhani, I., Ketabi, A., and Feuillet, R.2012. Radial Basis Function Neural Network Application to Power System Restoration Studies.Hindawi Publishing Corporation Computational Intelligence and Neuroscience

[30] Abd-Elkader, A.G., Allam, D. F., Tageldin, E.2014. Islanding detection method for DFIG wind turbines using artificial neural Networks. Elsevier- Electrical Power and Energy Systems, vol.62, pp.335-343

[31] Priya, R., Prakash, S.2014. Optimal Location and Sizing of Generator in Distributed Generation System. International Journal of Innovative Research in Electrical, Electronics, Instrumentation and Control Engineering, Vol. 2, Issue. 3

[32] Harrison, G. P., Piccolo, A., Siano, P., Wallace, A R.2007. Distributed Generation Capacity Evaluation Using Combined Genetic Algorithm and OPF. International Journal of Emerging Electric Power Systems, Vol.8, Iss.2

[33] Behbahani, H. H., Zanganeh, A., Abdi, B.2014. Transient stability assessment of power systems using Support Vector Machine (SVM) with distributed generation units International Journal Of Science And Research, Vol. 2, pp.20-27 